\title{
Psychobiology of social support: The social dimension of stress buffering
}

\author{
Beate Ditzen $^{\mathrm{a}, *}$ and Markus Heinrichs ${ }^{\mathrm{b}, \mathrm{c}, *}$ \\ ${ }^{a}$ Division of Clinical Psychology and Psychotherapy, Department of Psychology, University of Zurich, \\ Zurich, Switzerland \\ ${ }^{\mathrm{b}}$ Laboratory for Biological and Personality Psychology, Department of Psychology, University of Freiburg, \\ Freiburg, Germany \\ ${ }^{\mathrm{c}}$ Freiburg Brain Imaging Center, University Medical Center, University of Freiburg, Freiburg, Germany
}

\begin{abstract}
Social integration and social support have a substantial influence on individual health and longevity, an effect assumed to be mediated through reduced stress reactivity in support recipients. However, considerable variability in individual responses to social support has been documented, suggesting that the beneficial effect of social support interacts with early experiences, genetically influenced differences in biological systems mediating social behavior, personality traits, and psychopathology. Here we outline the historical background of social support research, including epidemiological studies, laboratory studies, and field studies on the subject of social support and health, with regard to different psychobiological effector systems. Most recent research has focused on brain mechanisms which link social integration or social support with reduced neural threat responses. As numerous mental disorders are associated with considerable social impairment, understanding the potentially underlying mechanisms of neural plasticity in relation to social support, stress buffering and health in these disorders can help tailor new diagnostic and treatment strategies. Thus, theories of socially-driven emotional learning and memory, as presented in this review, might eventually lead to psychobiology-based treatment concepts for mental disorders involving social deficits.
\end{abstract}

Keywords: Social support, stress, psychobiology, autonomic nervous system (ANS), hypothalamus pituitary adrenal (HPA) axis, cortisol, oxytocin, safety signals

\section{Introduction}

Being integrated in close social relationships or perceiving that social support would be available in case of need has considerable consequences for an individual's health and even survival (Berkman et al., 2000;

\footnotetext{
*Corresponding author: Beate Ditzen, Ph.D., Clinical Psychology and Psychotherapy, Department of Psychology, University of Zurich, Binzmuhlestrasse 14/Box 26, CH-8050, Zurich, Switzerland. Tel.: +41 44635 7365; Fax: +41 44635 7359; E-mail: b.ditzen@psychologie.uzh.ch; Markus Heinrichs, Ph.D., Laboratory for Biological and Personality Psychology, Department of Psychology, University of Freiburg, Stefan-Meier-Strasse 8. D79104 Freiburg, Germany. Tel.: +49 761203 3024; Fax: +49 761 203 3023; E-mail: heinrichs@psychologie.uni-freiburg.de.
}

Holt-Lunstad et al., 2010; Seeman, 2000), with effect sizes equaling or exceeding those of well-established behavioral factors, such as smoking-cessation, sports, or absenteeism from alcohol. Seeking rewarding social interactions starts in early life and evolves into various forms of social attachment throughout the life cycle (Ainsworth, 1991; Bowlby, 1969). New experimental paradigms and technologies in human research allow a more nuanced investigation of the molecular basis of the link between social integration, social support and health. The fact that most mental disorders are associated with considerable social deficits make these research tools particularly well-suited for new psychobiology-based diagnostic and treatment strategies. 
Here we begin by sketching the historical background of social support research, presenting epidemiological studies, laboratory studies, and field studies on the subject of social support and health. Then, we summarize more recent findings on the central nervous mechanisms of social support, which will lead to a psychobiological model. We assume that positive social interaction, namely social support, can activate comparable principles of emotional learning as have been established for fear-learning processes (Olsson \& Phelps, 2007). Consequently, combining principles of learning and brain plasticity with those of social support, might help develop therapeutic tools for the treatment of various stress-related diseases and disorders with severe social deficits.

\section{Social support and health: Historical overview}

The foundations for theoretical research addressing the association between social support and health and later on for the analysis of biological factors in the laboratory were laid in the 1960 s by epidemiological studies. Among other things, these studies demonstrated a greater quality of life in persons with at least one close confidant (Lowenthal \& Haven, 1968) and a higher death rate of widowed persons (Parkes et al., 1969). In an overview lecture in 1976, Cassel summarized the influence of different social factors - including social support - on the immune capacity of people in modern Western societies. In the same year, in an overview article, Cobb (1976) specifically described the influence of social support on a diversity of health factors. These works were later followed by seminal epidemiological studies (for an overview, cf. Broadhead et al., 1983).

In a first study comprising 4775 adults in Alameda County, California, Berkman \& Syme (1979) found that social integration, measured according to marriage, contact with friends and family, membership of religious communities and other forms of formal and informal group membership, reduced relative mortality risk 9 years following the data collection by approximately $50 \%$. In another large epidemiological study (2754 participants) in Tecumseh, Michigan, House et al. (1982) reached the same conclusions and were additionally able to support their results by including several medical risk factors (e.g., blood pressure, cholesterol level) from a medical baseline examination as control variables. Finally, Schoenbach et al. (1986) replicated these findings in a sample of 2059 persons in Evans County, Georgia, taking into consideration age, medical and self-reported health risk factors.

Studies in Scandinavia reached similar outcomes (Kaplan et al., 1988; Orth-Gomer \& Johnson, 1987; Welin et al., 1985). Although several of the cited studies (House, et al., 1982; Orth-Gomer \& Johnson, 1987; Schoenbach, et al., 1986) suggest a lower protective effect of social integration in women compared to men, all of the studies - including more recent ones (Herlitz et al., 1998; Knox et al., 2000) - are unequivocal in terms of their basic assertion: People who perceive themselves to be socially integrated and supported lead healthier, happier and longer lives - and conversely, lonely people are faced with a clearly increased health risk (Rozanski et al., 1999; Uchino et al., 1996).

Recently, in a meta-analytical analysis Holt-Lunstad and colleagues (2010) compared the effects of these and other studies with other well-established behavioral health-promoting factors, such as physical activity or reducing smoking or alcohol consumption. Their analysis confirmed the above listed findings and, strikingly, suggested that social integration and social support had even stronger effects on longevitiy than any of the other investigated factors.

\section{Terms and definitions}

In view of these results, it is helpful to keep the central concepts in mind which define social support. Over the years, social support has been more precisely defined based on its effects, duration, structure, and relationship with other health-relevant psychobiological concepts.

\subsection{Effects of social support on health vs. effects of health on social support}

The question arises of whether a) people in stable relationships lead healthier lives than those who are socially isolated or b) healthy people lead more socially integrated lives than unhealthy people. Thus, although the association has been repeatedly shown, its causality is not yet clear. In favor of the first hypothesis, there is extensive literature suggesting that social support increases medication compliance (Institute of Medicine Committee on Health and Behavior, 2001; Levy, 1983). This effect might be indirectly mediated 
through the facilitation of health behavior in a regulated social context and the internalization of norms. On the other hand, the effect might also be regulated directly through the social control of health behavior (such as the threat of leaving one's partner if he or she continues to drink) (Umberson, 1987). However, Cohen et al. (1997) were able to demonstrate that besides health beneficial behavior per se, there must be a direct mechanism that explains the positive influence of support on health (c.f. also Cacioppo et al., 2002; Pressman \& Cohen, 2005).

The second argument, the so-called "selection hypothesis", assumes that rather than social relationships improving health, people who are already healthy are intrinsically more likely to enter into close and lasting relationships and also more likely to be selected as attachment partners (for a discussion, see Burman \& Margolin, 1992; Umberson, 1987). Epidemiological studies have attempted to control for this factor in baseline measurements (Berkman \& Syme, 1979; House, et al., 1982), and the results speak more in favor of a direct influence of the social relationship on health than vice versa. However, the most methodologically sound way of controlling for the factors involved is to conduct a laboratory study in which the effects of acute social support on specific health-relevant parameters are examined in persons with comparable social relationships under standardized conditions. In the following, we will briefly describe some important conceptual distinctions inherent in this kind of support research, with the aim of enabling a better classification of the subsequent findings.

\subsection{Perceived support vs. received support}

In order to interpret the findings from support research in the laboratory and in the field, it is important to draw a distinction between two concepts: perceived support and received support. Perceived support is understood as a general expectation of being supported, an expectation which remains relatively stable over several years (Sarason et al., 1986), and which has therefore been interpreted as part of the selfconcept, i.e., as a personality trait (Sarason et al., 1990). Received support in contrast describes an intended and observable act of help (including all functional types which are outlined below) and is assessed by means of behavior observation and behavior coding (e.g., Pasch et al., 2004). Interestingly, perceived support appears to be only weakly connected to actual support receipt and also seems to be a much better predictor of healthrelevant outcomes than received support (e.g., Cohen \& Hoberman, 1983).

\subsection{Visible support vs. invisible support}

This discrepancy between self-evaluated general support availability and actual support receipt has stimulated intense discussions in research and, more recently, led to a further distinction between types of received social support: visible versus invisible social support (Bolger et al., 2000; Shrout et al., 2006). Invisible support is supposed to at least in part bridge the gap between the two concepts because possible selfdiminishing aspects of receiving support disappear. Invisible support can be provided in a way that the recipient does not even realize that it is occurring (e.g., helping in the household without one's partner noticing), or in a way that it might not be interpreted as support in a narrower sense (e.g., when a friend gives advice in an indirect way or in a context not directly related to the stressful situation). Invisible support might therefore exert all of the positive effects of visible support, while the negative effects (such as the discrepancy between the support demanded and provided) disappear. It might, thus, influence health outcomes through a more indirect perception of being supported, however to our knowledge this hypothesis has not yet been tested with regard to biological outcomes.

\subsection{Functional differences}

Finally, most studies on social support are based on different functional aspects of support. In the beginning of the 1990 s, Schwarzer \& Leppin (1991) described different kinds of support, such as instrumental support (to assist with a problem), tangible support (to donate goods), informational support (advice), or emotional support (e.g., reassurance). In the same vein, more recently Barrera \& Ainlay (2006) distinguished directive guidance, non-directive support, positive social interaction, and tangible assistance. Today, most social support concepts subsume these different functional aspects and distinguish at least two forms, namely practical or instrumental support (i.e., help or guidance) in contrast to psychological or emotional support (appraisal or non-verbal supportive acts, such as hugging or hand-holding; c.f., Reis, 1996). 


\section{Social support as a "stress buffer"}

Stress is considered a principal cause for a series of health problems, irrespective of the physical system affected (Adler \& Matthews, 1994; McEwen, 1998). Also, dysregulated stress systems have been related to a variety of mental disorders (Chrousos, 2009). By reducing overall stress levels, social support might therefore promote health in the long term (Cobb, 1976) and two possible mechanisms have been suggested to mediate the influence of social support on health: a main effect and a so-called buffer effect (Broadhead et al., 1983; Cohen, 1988; Cohen \& Wills, 1985; Wheaton, 1985). The main effect of social support describes a direct positive effect of support on various health parameters irrespective of stressors. The buffer effect is understood as the reduction of negative effects of stress on health through social support. These two effects can be tested against one another - but they can also exist alongside one another without any difficulty. Thus, social support might indeed have a direct, positive effect on physical systems and in addition alleviate the negative effects of stress.

Studies measuring the effect of social support on biological parameters therefore share the methodology that participants are confronted with a stressor in order to enable main effects and buffer effects to be measured. Outcomes of autonomic nervous system activation, activation of the hypothalamic-pituitaryadrenal (HPA) axis or the immune system are then assessed as dependent variables in the laboratory or in the field.

To our knowledge, the first laboratory study to look explicitly at the effect of social support on the psychobiological stress response was published almost 50 years ago by Kissel (1965). Based on pre-ratings on "affiliation motivation", Kissel examined 96 participants with high affiliation motivation or with low affiliation motivation who were tested alone, with an unknown supporting person or with an acquainted supporting person. Participants were presented with several unsolvable tasks and state anxiety and palmar skin conductance (assessed in micromho, with electrodes taped to the first and third finger of the subject's nondominant hand) were recorded as dependent stress markers. In general, social support was found to reduce skin conductance, and this finding was most apparent when the support provider was acquainted with the participant. Moreover, only these supporters were able to significantly reduce the participants' anxiety.
In the following, we will review effects of social support on cardiovascular, endocrine, and immune parameters in controlled laboratory experiments and in individuals' everyday lives.

\subsection{Social support and the autonomic nervous system}

Overall, self-reported perceived support has been associated with reduced autonomic activation, e.g., reduced norepinephrine (Fleming et al., 1982) or epinephrine levels (Knox et al., 1985; Seeman et al., 1994). Autonomic activation can also be noninvasively assessed through indirect markers, such as heart rate, blood pressure, or skin conductance, although these measures do not necessarily correlate. Consequently, most studies rely on parallel assessments of different autonomic parameters in relation to social support, among others Evans \& Steptoe (2001), who reported an association of social support at work with heart rate, but not with blood pressure and cortisol during the working day.

The first laboratory studies addressing the effect of instructed social support on physiological systems focused on cardiovascular parameters as indicators of autonomic activation or stress. In general these studies suggested reduced autonomic activation to stress when another person was present (Kamarck et al., 1990), ideally a woman (Glynn et al., 1999). This stress-buffering effect was even pronounced when the participant knew the supporting person well (eg. a close friend, Christenfeld et al., 1997; Edens et al., 1992; Uno et al., 2002). However, it is not only the relationship with the supporting person that determines the reactivity of the autonomic nervous system, but also the quality of the interaction itself. For instance, positive supportive behavior reduced blood pressure and heart rate in comparison to neutral or negative behavior (Gerin et al., 1992; Lepore et al., 1993). In this respect, nonevaluative support (e.g., the presence of one's own pet) appears to have the strongest effects (Allen et al., 2002; 1991). Overall, the more aversive or threatening the situation is, the more effective social support seems to be (Kiecolt-Glaser \& Greenberg, 1984; Lepore, 1995).

This association appears to be stronger for women than for men (Linden et al., 1993), to apply more strongly for contact with family members than for contact with acquaintances or unknown persons (Spitzer et al., 1992), and to be particularly visible under conditions of stress (Karlin et al., 2003; Steptoe, 2000). 
Interestingly, giving support also seems to have a positive effect on autonomic parameters and on health, albeit through different mechanisms of action than receiving support: Piferi \& Lawler (2006) were able to show that providing support reduces stress reactivity (systolic blood pressure) in everyday life through increased self-efficacy - receiving support showed a direct negative effect on stress.

\subsection{Social support and the hypothamalamic- pituitary-adrenal axis}

In order to examine the assumed buffer effect of social support on the biological stress response, endocrine mechanisms such as the activity of the HPA axis have been examined. In one of the first studies in this field, Kirschbaum et al. (1995) compared men and women in terms of their stress response to the "Trier Social Stress Test" (TSST: a standardized laboratory stress test, consisting of a mock job interview and a mental arithmetic task in front of an audience; Kirschbaum et al., 1993) and compared instructed social support provision from one's own partner, support by an unknown person and a no-support condition. In line with the results of the aferomentioned studies, they found that men benefited the most from support provided by their partner - while women did not benefit from the support of their partner at all. In our own studies, we were able to replicate these findings (Ditzen et al., 2007; Heinrichs et al., 2003). Men benefited from verbal support (Heinrichs, et al., 2003); however, women showed increased heart rate and cortisol levels to verbal social support provided by their partner (Ditzen, et al., 2007) and benefited more from standardized touch (neck-shoulder massage) without verbal support (see Fig. 1). These results are consistent with the interpretation that women benefit more from non-judgemental but nonverbal reassurance, such as hugs, touch or smiling, than from verbal instruction and advice.

In line with this interaction between participant sex and response to social support, data from Smith and colleagues (Smith et al., 2009) suggest an interaction effect of sex and closeness in the effects of social support on cortisol responses to the TSST. Whereas men in an experimentally induced "high closeness condition" with a stranger showed increased cortisol responses to receiving support, women showed no such effect and overall no cortisol changes during the experiment. In another, more recent, combination of laboratory and field studies, Taylor and colleagues (2010) found the most pronounced cortisol responses in both men and women to a supportive audience in the TSST (as compared to a less supportive or no audience). Daily general support levels did not moderate this condition effect on cortisol stress responses; however, high levels of daily social support appeared to accelerate cortisol recovery in the non-supportive audience condition.

In everyday life, results on the link between social support and endocrine parameters are inconsistent, with various studies showing no effects at home (Luecken et al., 1997) or in the workplace (Evans \& Steptoe, 2001), or reduced daily cortisol (Evolahti et al., 2006) or steeper declines in afternoon cortisol levels (Karb et al., 2012) in those with higher levels of perceived social support.

\subsection{Social support and the immune system}

A further mechanism that has been suggested for explaining the association between social support and health on the biological level is the immune system. Various immune parameters have so far been investigated in relation with social support, including natural killer cell activity (NKA) as a relatively general first stage of the cellular immune response, tumor necrosis factor (TNF) levels and cytokine levels (e.g, IL1) as markers of immune competence as well as the immune status following vaccinations. To our knowledge, however, these links have not been tested under laboratory stress conditions but in the field, meaning that perceived social support rather than instructed received support has been measured.

Studies investigating associations between social support and immune system parameters will not be covered here in detail, and the reader is referred to review papers (DeVries et al., 2007; Karelina \& DeVries, 2011; Kiecolt-Glaser \& Newton, 2001; Spiegel \& Sephton, 2001) for a comprehensive account of the role of immune parameters in the beneficial effects of social support.

Taken together, available data indicate a strong effect of social support on health and suggest that this effect might be mediated through stress buffering effects on the level of the autonomic nervous system, the HPA axis and the immune system. These biological stress systems all share CNS mechanisms as their basis and feedback regulator. Consequently, with more recent techniques to monitor and pharmacologically modulate CNS mechanisms relevant for social interac- 

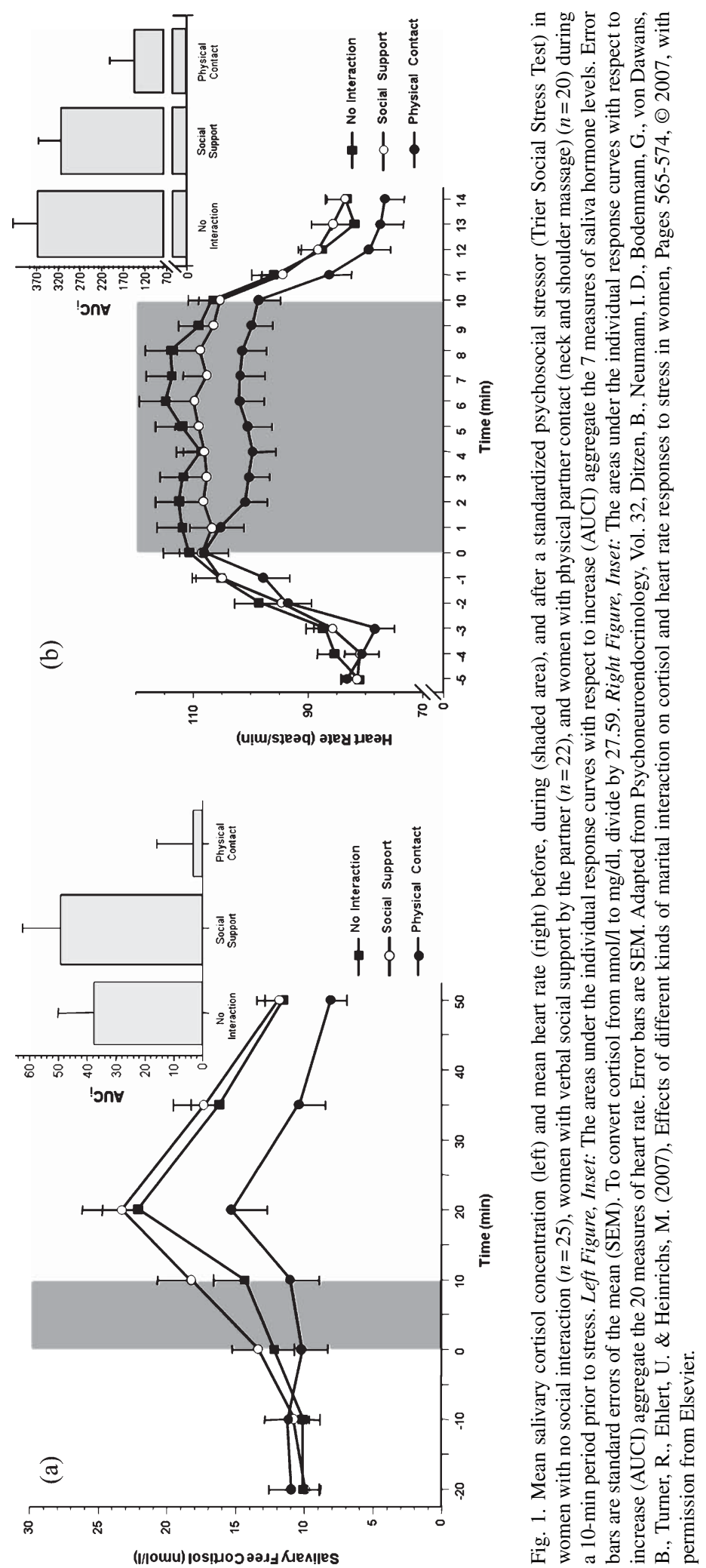
tion, research has turned towards these mechanisms in relation to social support and their effects on biological stress systems.

\subsection{Social support and the central nervous system}

The CNS mechanisms supposed to modulate the effects of social support on biological stress responses consist of brain areas and neuronal mechanisms that on the one hand mediate social motivation - i.e., make social interaction more rewarding - and on the other hand mechanisms that decrease stress reactivity. As early as 1984, Mendoza \& Barchas (1984) theorized that social integration should be linked to a survival advantage for the individual and, thus, lead to genetic selection of those individuals for whom social interaction is directly rewarding. Indeed in female support providers it has recently been shown, that giving support to the male partner (holding his hand while he received electric shocks) increased activation of the ventral striatum (VS), a reward-related region which is part of the mesolimbic dopaminergic system (Inagaki $\&$ Eisenberger, 2012). These results are in line with the above stated effects of giving support on autonomic stress levels (Piferi \& Lawler, 2006) and suggest that these effects might be mediated through reward-related CNS mechanisms.

With regard to the buffering hypothesis, a recent study found social support in everyday life to be related to reduced activity of the dorsal portion of the anterior cingulate cortex (dACC) and of Brodmann Area 8 in the dorsal superior frontal gyrus (Eisenberger et al., 2007) during a social rejection task. Based on these results, the authors hypothesized that social support might have desensitized the dACC over time through the release of opioids, which then in turn could reduce stress responses triggered by the dACC. In line with this, Coan and colleagues (2006) showed that when an experimenter or the participant's partner held the hand of female participants, thereby providing support, during the anticipation of threat, this reduced activation in brain regions including the ventral anterior cingulate cortex (vACC), the right dorsolateral prefrontal cortex (DLPC), the left caudate, superior colliculus, and posterior cingulate. The authors interpret these results as evidence of threat-reducing effects of hand-holding, particularly in the partner condition. As supposedly no physical hand-holding differences between the experimenter/partner conditions can explain the effects of partner hand-holding, these results are particularly interesting in light of learned social support effects within couples. They suggest that the closeness to the support-provider might have driven these effects, an effect which will be further discussed below.

The mere viewing of a photograph showing the attachment figure can lead to increased activity in the ventromedial prefrontal cortex (VMPC) and reductions in pain to standard heat pain stimuli (Eisenberger et al., 2011). These results were interpreted in terms of safety-inducing properties of the attachment figure. The VMPC has been previously related to learning of safety signals and with extinction of fear learning (eg. Phelps et al., 2004; Schiller et al., 2008) and, intriguingly, is thought to reduce amygdala activation during fear extinction (Quirk et al., 2006). Thus, the fact that seeing pictures of an attachment (support) figure alone can trigger VMPC activation during pain suggests that social support might excert its effects in the brain by means of conditioned safety signals (see below), an effect with high relevance for health. Research on the neural underpinnings of empathy - an important predictor of providing/acknowledging effective social support - suggests that receiving painful stimulation to the own hand or observing one's partner receiving painful stimulation to the hand both activate identical somatosensory (Bufalari et al., 2007), sensorimotor (Avenanti et al., 2005) and affective components of the pain matrix (anterior insula, AI, and anterior cingulate cortex, ACC) (Singer et al., 2004, 2008).

In addition to these neuroanatomical and neurofunctional findings, in recent years research has increasingly focused on neuropeptides in the brain and their role in the regulation of social behavior. Besides the consistent data from animal studies showing an involvement of the neuropeptides oxytocin and vasopressin in social behavior, anxiety, and stress regulation (Insel, 2010; Young \& Wang, 2004), there is growing literature suggesting that these very same mechanisms are involved in the regulation of human sociality (Meyer-Lindenberg et al., 2011). Since it was demonstrated that intranasally administered neuropeptides reach the brain (for vasopressin, see Born et al., 2002; with regard to oxytocin, see recent data from Chang et al., 2012), several studies have investigated the effects of oxytocin (and to a lesser extent of vasopressin) intranasal administration on social behavior in humans, specifically when receiving social support (Heinrichs et al., 2009). In an initial randomized, double-blind study, Heinrichs et al. (2003) applied either oxytocin (24 IU) or placebo intranasally to male 

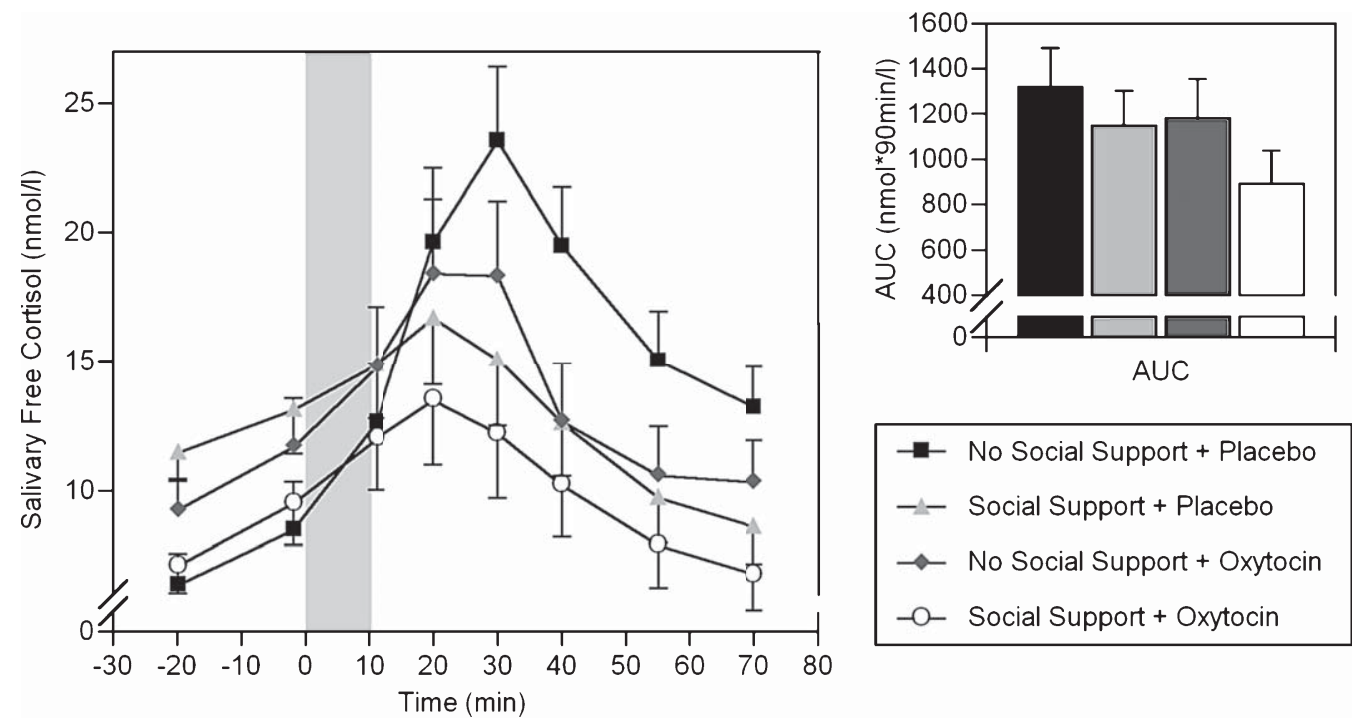

Fig. 2. Mean salivary free cortisol concentrations $( \pm$ SEM) during psychosocial stress exposure (Trier Social Stress Test). Participants were randomly assigned to receive intranasal oxytocin $(24 \mathrm{IU})$ or placebo and either no social support or social support from their best friend before stress. The shaded area indicates the period of the stress tasks (public speaking followed by mental arithmetic in front of a panel of evaluators). Inset: The areas under the individual response curves (AUC) represent cumulative cortisol release (calculated by aggregating data from 8 saliva sampling points) throughout the session. Significant interaction effects on cortisol were observed (social support by time effect, $p<0.001$; social support by oxytocin by time effect, $p<0.01$ ). Figure modified from Biological Psychiatry, Vol. 54, Heinrichs, M., Baumgartner, T., Kirschbaum, C., \& Ehlert, U. (2003), Social support and oxytocin interact to suppress cortisol and subjective responses to psychosocial stress, Pages 1389-1398, with permission from @ 2003 Society of Biological Psychiatry.

participants prior to their participation in the TSST. In order to measure possible associations with social support receipt, half of the participants were randomly selected to receive verbal support from their best friend, while the other half came to the experiment alone. As expected, social support led to a significantly lower endocrine (cortisol) and psychological stress response (anxiety, restlessness). Interestingly, however, the combination of social support with increased central nervous oxytocin availability resulted in the lowest stress reactions: participants with both protective factors showed the lowest cortisol stress reactions and the lowest anxiety and tension over the course of the stress test (see Fig. 2).

This positive effect of the combination of social support with oxytocin seems to be mediated through reduced amygdala activation (cf. experiments on the cellular level: Huber et al., 2005), particularly during presentation of socially relevant stimuli (emotional faces) (Domes, Heinrichs, Glascher, et al., 2007; Kirsch et al., 2005). Overall, the modulation of social behavior by oxytocin has been confirmed in a large number of studies using different paradigms, e.g., trust behavior (Baumgartner et al., 2008; Kosfeld et al.,
2005), cooperation (Rilling et al., 2012), couple interaction (Ditzen, Nater, et al., 2012; Ditzen et al., 2009), and social cognition, namely empathic evaluation of emotions (Domes, Heinrichs, Michel, et al., 2007; Rodrigues et al., 2009). Also, most recent genetic data suggest that polymorphisms in the oxytocin receptor (OTR) gene modulate whether and how much individuals benefit from social support receipt during stress (Chen et al., 2011; Kim et al., 2010), from attachment relationships in the face of trauma (Bradley et al., 2011; Ditzen, Bradley, et al., 2012), or, in contrast, suffer from depression and social anxiety in the context of mothers' history of recurrent major depressive disorder (Thompson et al., 2011) (for review, see Kumsta \& Heinrichs, 2013).

Thus in a recent study, Chen and colleagues (2011) found that a common single nucleotide polymorphism (rs53576) in the OTR gene in men interacted with the effects of social support provided by a female supporter on cortisol stress responses to the TSST. Men with one or two copies of the $\mathrm{G}$ allele of rs53576 seemed to benefit more from social support (resulting in lower cortisol responses), compared with men with the same genotype receiving no social support (see Fig. 3). 


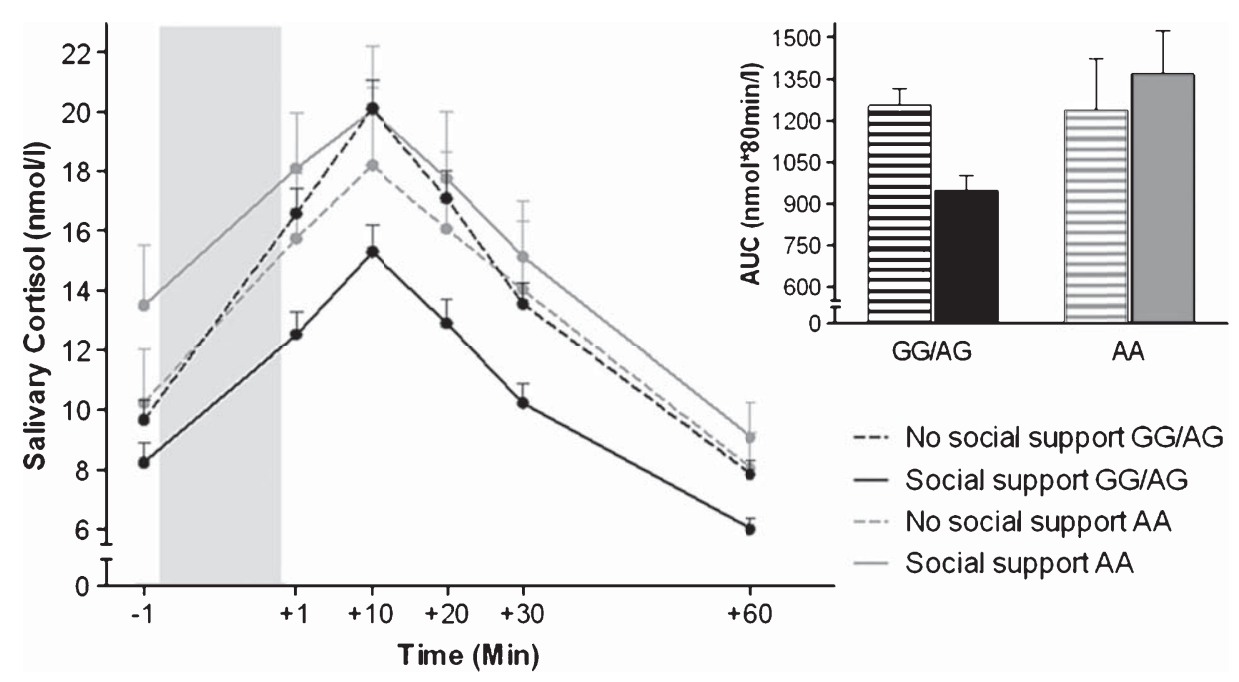

Fig. 3. Interaction between genotype OTR SNP rs53576 (AA vs. G carriers) and social support on cortisol responses. Individuals with one or two copies of the $\mathrm{G}$ allele of rs53576 showed lower cortisol responses to stress after social support, compared with individuals with the same genotype receiving no social support. Figure depicts mean salivary cortisol levels before, during (shaded area), and after acute social stress in individuals receiving social support or no social support. Error bars represent SEM. Inset: Bar graph of area under the response curves (AUC), representing aggregated hormone levels through the six measurement points. Figure modified from Proceedings of the National Academy of Sciences of the United States of America, Vol. 108, Chen, F. S., Kumsta, R., von Dawans, B., Monakhov, M., Ebstein, R. P., \& Heinrichs, M. (2011), Common oxytocin receptor gene (OXTR) polymorphism and social support interact to reduce stress in humans, Pages 19937-19942, with permission from (C) 2011 the National Academy of Sciences USA.

These genetic data also link the oxytocin system with morphometric alterations of the hypothalamus and amygdala (Furman et al., 2011; Inoue et al., 2010; Tost et al., 2010) as well as reward mechanisms in the brain, such as the dopamine system (Love et al., 2012).

\subsection{Social support in psychiatric disease: disturbances in social cognition}

Most psychopathology is, at least in some parts, associated with impaired social functioning (American Psychiatric Association, 2000). More specifically, some mental disorders are explicitly based on impaired social cognition, e.g., autism spectrum disorders or social phobia. Whereas social support in general is associated with stress buffering and thereby might ameliorate suffering from psychiatric disease, individuals affected with impaired social cognition might not benefit from the support provided. The fact that precisely those disorders which are related to impaired social cognition have recently been related to altered oxytocin functioning, might suggest neuropharmacological treatment options in the long term (Meyer-Lindenberg, et al., 2011) and, thus, help translate results from neuroscience into clinical practice.

\section{Bridging the gap: Social support, learning and brain plasticity}

Social aspects of fear learning have received considerable scientific interest (Olsson, 2011; Olsson \& Phelps, 2007), and there is abundant data suggesting amygdala-centered social fear learning by observing others. The ability to appropriately respond to fear signals in our environment is essential for survival, and social learning of these signals is thus highly adaptive.

We do however not only communicate about fearprovoking signals or learn to react with adequate fear due to classical conditioning, but also about safety from harm. Whereas research on CNS mechanisms mediating social aspects of safety signaling is to date relatively limited, the available data suggest that the same amygdala-driven processes implicated in fear learning might also be involved in the processing of safety signals. In line with this, reduced threat-related neural activity (i.e., amygdala activation) has been found to affect social interaction and social support, or the mere activation of attachment/support related emotional concepts (as, for example, by viewing pictures of a loved one). Also, as outlined above, neuroendocrine studies suggest specific involvement of neuropeptides 
(most prominently oxytocin) in stress-buffering on the CNS level. We here argue that, in parallel to social fear learning, humans are prone to social safety learning, and that these processes can be enhanced through consistent and repeated experiences of social support from early childhood on. Furthermore, the above-mentioned genetic variation of the oxytocin receptor gene may influence the efficacy of social support by influencing the reward value of social interaction early in development. Children who find social interaction more rewarding may be more likely to form positive associations with the experience of seeking social support; later in life, the cumulative effects of these experiences may manifest themselves as differential tendencies to seek and benefit from social support. All forms of social support which were mentioned before might be involved in this process. Whereas repeatedly received support would be expected to modulate stable support expectancies and overall support perceptions, invisible support might at the same time increase an individual's sense of competency in coping with different stressors. As one of cognitive behavioral therapy's (CBT) principles is to provide support in motivation and behavior change (Lambert, 2013), several CBT components might be suited to establish and condition social support experiences as learned safety signals. In patients suffering from psychopathology associated with impaired social cognition, however, social support and psychotherapy alone might not be sufficient to modulate these hypothesized effects. In these patients, results from neuroendocrine studies support a model in which pharmacological manipulation of neuropeptide availability might improve social cognition and could, thus, help them to benefit from supportive or social interaction-based interventions (Meyer-Lindenberg, et al., 2011).

\section{Summary}

The positive effect of social support on health has been well documented for several decades now. Laboratory studies conducted since the beginning of the 1990 s suggest that social support, besides it's effects on health behavior, exerts a direct effect on physical systems, but also acts as a buffer, especially under conditions of stress. Under stress, non-evaluative support in particular seems to have a positive influence on the response of the autonomic nervous system, the HPA axis, and the immune system. In the last few years, these effects have been investigated using imaging and neuroendocrine methods directly at the level of the CNS, and it has been shown that social integration and social support are associated with reward-relevant and anxiety-reducing structures and transmitter systems. These systems can, in turn, effectively reduce biological stress reactivity. Thus, the results of the studies presented here from epidemiological research, laboratory and field research on various biological stress parameters, and brain imaging or neuroendocrine research, complement one another. These data are in line with a model in which social integration and repeated social support experiences are interpreted as safety signals which modulate threat processing in the CNS and the periphery of the body. The translation of these findings into clinical applications will, thus, improve individual health by helping to tailor new diagnostic and treatment strategies for stress-related disorders and mental disorders with social deficits.

\section{Acknowledgments}

B.D. would like to thank the Swiss National Science Foundation (SNF) for providing a postdoctoral grant (PBZH1-108392) and individual project funding (SNF 105314 124627), as well as the University of Zurich for providing a young investigator research grant. M.H. gratefully acknowledges grant support from the Deutsche Forschungsgemeinschaft (DFG) (HE 5310/1-1; DA 1416/2-1). Note: In some parts this paper refers to previously published text parts from a German publication by the authors from 2007.

Ditzen, B., \& Heinrichs, M. (2007). Psychobiologische Mechanismen sozialer Unterstuetzung. Zeitschrift fur Gesundheitspsychologie, 15(4), 143-157.

\section{References}

Adler, N. \& Matthews, K. (1994). Health psychology: Why do some people get sick and some stay well? Annu Rev Psychol, 45, 229-259.

Ainsworth, M. (1991). Attachments and other affectional bonds across the life cycle. In Parkes, C.M., Stevenson-Hinde, J. \& Marris P. (Eds.), Attachment across the life cycle. New York: Routledge, pp. 33-51.

Allen, K., Blascovich, J. \& Mendes, W.B. (2002). Cardiovascular reactivity and the presence of pets, friends, and spouses: The truth about cats and dogs. Psychosom Med, 64(5), 727-739. 
Allen, K., Blascovich, J., Tomaka, J. \& Kelsey, R.M. (1991). Presence of human friends and pet dogs as moderators of autonomic responses to stress in women. J Pers Soc Psychol, 61, 582-589.

American Psychiatric Association. (2000). Diagnostic and Statistical Manual of Mental Disorders (DSM-IV-TR) (4 ed.). Washington, DC: American Psychiatric Association.

Avenanti, A., Bueti, D., Galati, G. \& Aglioti, S.M. (2005). Transcranial magnetic stimulation highlights the sensorimotor side of empathy for pain. Nat Neurosci, 8(7), 955-960.

Barrera, M. \& Ainlay, S.L. (2006). The structure of social support: A Conceptual and empirical analysis. J Community Psychol, 11(2), 133-143.

Baumgartner, T., Heinrichs, M., Vonlanthen, A., Fischbacher, U. \& Fehr, E. (2008). Oxytocin Shapes the Neural Circuitry of Trust and Trust Adaptation in Humans. Neuron, 58(4), 639-650.

Berkman, L.F., Glass, T., Brissette, I. \& Seeman, T.E. (2000). From social integration to health: Durkheim in the new millennium. Soc Sci Med, 51(6), 843-857.

Berkman, L.F. \& Syme, S.L. (1979). Social networks, host resistance and mortality: A nine-year follow-up study of Alameda County residents. Am J Epidemiol, 109, 186-204.

Bolger, N., Zuckerman, A. \& Kessler, R.C. (2000). Invisible support and adjustment to stress. J Pers Soc Psychol, 79(6), 953-961.

Born, J., Lange, T., Kern, W., McGregor, G.P., Bickel, U. \& Fehm, H.L. (2002). Sniffing neuropeptides: A transnasal approach to the human brain. Nat Neurosci, 5(6), 514-516.

Bowlby, J. (1969). Attachment (Vol. 1). New York: Basic Books.

Bradley, B., Westen, D., Mercer, K.B., Binder, E.B., Jovanovic, T., Crain, D., Wingo, A. \& Heim, C. (2011). Association between childhood maltreatment and adult emotional dysregulation in a low-income, urban, African American sample: Moderation by oxytocin receptor gene. Dev Psychopathol, 23, 87100.

Broadhead, W.E., Kaplan, B.H., James, S.A., Wagner, E.H., Schoenbach, V.J., Grimson, R., Heyden, S., Tibblin, G. \& Gehlbach, S.H. (1983). The epidemiologic evidence for a relationship between social support and health. Am J Epidemiol, 117(5), 521-537.

Bufalari, I., Aprile, T., Avenanti, A., Di Russo, F. \& Aglioti, S.M. (2007). Empathy for pain and touch in the human somatosensory cortex. Cereb Cortex, 17(11), 2553-2561.

Burman, B. \& Margolin, G. (1992). Analysis of the association between marital relationships and health problems: An interactional perspective. Psychol Bull, 112(1), 39-63.

Cacioppo, J.T., Hawkley, L.C., Crawford, L.E., Ernst, J.M., Burleson, M.H., Kowalewski, R.B., Malarkey, W.B., Van Cauter, E. \& Berntson, G.G. (2002). Loneliness and health: Potential mechanisms. Psychosom Med, 64(3), 407-417.

Cassel, J. (1976). The contribution of the social environment to host resistance: The Fourth Wade Hampton Frost Lecture. Am J Epidemiol, 104(2), 107-123.

Chang, S.W., Barter, J.W., Ebitz, R.B., Watson, K.K. \& Platt, M.L. (2012). Inhaled oxytocin amplifies both vicarious reinforcement and self reinforcement in rhesus macaques (Macaca mulatta). Proc Natl Acad Sci U S A, 109(3), 959-964.
Chen, F.S., Kumsta, R., von Dawans, B., Monakhov, M., Ebstein, R.P. \& Heinrichs, M. (2011). Common oxytocin receptor gene (OXTR) polymorphism and social support interact to reduce stress in humans. Proc Natl Acad Sci U S A, 108(50), 1993719942.

Christenfeld, N., Gerin, W., Linden, W., Sanders, M., Mathur, J., Deich, J.D. \& Pickering, T.G. (1997). Social support effects on cardiovascular reactivity: Is a stranger as effective as a friend? Psychosom Med, 59(4), 388-398.

Chrousos, G.P. (2009). Stress and disorders of the stress system. Nat Rev Endocrinol, 5(7), 374-381.

Coan, J.A., Schaefer, H.S. \& Davidson, R.J. (2006). Lending a hand: Social regulation of the neural response to threat. Psychological Science, 17(12), 1032-1039.

Cobb, S. (1976). Social support as a moderator of life stress. Psychosom Med, 38, 300-314.

Cohen, S. (1988). Psychosocial models of the role of social support in the etiology of physical disease. Health Psychol, 7(3), 269297.

Cohen, S., Doyle, W.J., Skoner, D.P., Rabin, B.S., \& Gwaltney, J.M., Jr. (1997). Social ties and susceptibility to the common cold. JAMA, 277(24), 1940-1944.

Cohen, S. \& Hoberman, H.M. (1983). Positive events and social support as buffers of life change stress. Journal of Applied Social Psychology, 13, 99-125.

Cohen, S. \& Wills, T.A. (1985). Stress, social support, and the buffering hypothesis. Psychol Bull, 98(2), 310-357.

DeVries, A.C., Craft, T.K., Glasper, E.R., Neigh, G.N. \& Alexander, J.K. (2007). 2006 Curt P. Richter award winner: Social influences on stress responses and health. Psychoneuroendocrinology, 32(6), 587-603.

Ditzen, B., Bradley, B. \& Heim, C.M. (2012). Oxytocin and pair bonding: On possible influences during the life course. Biol Psychiatry, 72(3), e3-4.

Ditzen, B., Nater, U.M., Schaer, M., La Marca, R., Bodenmann, G., Ehlert, U. \& Heinrichs, M. (2012). Sex-specific effects of intranasal oxytocin on autonomic nervous system and emotional responses to couple conflict. Soc Cogn Affect Neurosci, in press, Epub ahead of print.

Ditzen, B., Neumann, I.D., Bodenmann, G., von Dawans, B., Turner, R., Ehlert, U. \& Heinrichs, M. (2007). Effects of different kinds of marital interaction on cortisol and heart rate responses to stress in women. Psychoneuroendocrinology 32, 565574.

Ditzen, B., Schaer, M., Bodenmann, G., Gabriel, B., Ehlert, U. \& Heinrichs, M. (2009). Intranasal oxytocin increases positive communication and reduces cortisol levels during couple conflict. Biol Psychiatry, 65(9), 728-731.

Domes, G., Heinrichs, M., Glascher, J., Buchel, C., Braus, D.F. \& Herpertz, S.C. (2007). Oxytocin attenuates amygdala responses to emotional faces regardless of valence. Biol Psychiatry, 62(10), 1187-1190.

Domes, G., Heinrichs, M., Michel, A., Berger, C. \& Herpertz, S.C. (2007). Oxytocin improves "mind-reading" in humans. Biol Psychiatry, 61(6), 731-733. 
Edens, J.L., Larkin, K.T. \& Abel, J.L. (1992). The effect of social support and physical touch on cardiovascular reactions to mental stress. J Psychosom Res, 36(4), 371-381.

Eisenberger, N.I., Master, S.L., Inagaki, T.K., Taylor, S.E., Shirinyan, D., Lieberman, M.D. \& Naliboff, B.D. (2011). Attachment figures activate a safety signal-related neural region and reduce pain experience. Proc Natl Acad Sci U S A, 108(28), 11721-11726.

Eisenberger, N.I., Taylor, S.E., Gable, S.L., Hilmert, C.J. \& Lieberman, M.D. (2007). Neural pathways link social support to attenuated neuroendocrine stress responses. Neuroimage, 35(4), 1601-1612.

Evans, O. \& Steptoe, A. (2001). Social support at work, heart rate, and cortisol: A self-monitoring study. J Occup Health Psychol, 6(4), 361-370.

Evolahti, A., Hultcrantz, M. \& Collins, A. (2006). Women's work stress and cortisol levels: A longitudinal study of the association between the psychosocial work environment and serum cortisol. J Psychosom Res, 61(5), 645-652.

Fleming, R., Baum, A., Gisriel, M.M. \& Gatchel, R.J. (1982). Mediating influences of social support on stress at Three Mile Island. J Human Stress, 8(3), 14-22.

Furman, D.J., Chen, M.C. \& Gotlib, I.H. (2011). Variant in oxytocin receptor gene is associated with amygdala volume. Psychoneuroendocrinology, 36(6), 891-897.

Gerin, W., Pieper, C., Levy, R. \& Pickering, T.G. (1992). Social support in social interaction: A moderator of cardiovascular reactivity. Psychosom Med, 54(3), 324-336.

Glynn, L.M., Christenfeld, N. \& Gerin, W. (1999). Gender, social support, and cardiovascular responses to stress. Psychosom Med, 61(2), 234-242.

Heinrichs, M., Baumgartner, T., Kirschbaum, C. \& Ehlert, U. (2003). Social support and oxytocin interact to suppress cortisol and subjective responses to psychosocial stress. Biol Psychiatry, 54(12), 1389-1398

Heinrichs, M., von Dawans, B. \& Domes, G. (2009). Oxytocin, vasopressin, and human social behavior. Front Neuroendocrinol, 30(4), 548-557.

Herlitz, J., Wiklund, I., Caidahl, K., Hartford, M., Haglid, M., Karlsson, B.W., Sjoland, H. \& Karlsson, T. (1998). The feeling of loneliness prior to coronary artery bypass grafting might be a predictor of short-and long-term postoperative mortality. Eur J Vasc Endovasc Surg, 16(2), 120-125.

Holt-Lunstad, J., Smith, T.B. \& Layton, J.B. (2010). Social relationships and mortality risk: A meta-analytic review. PLoS Medicine, 7(7), e1000316.

House, J.S., Robbins, C. \& Metzner, H.L. (1982). The association of social relationships and activities with mortality: Prospective evidence from the Tecumseh Community Health Study. Am J Epidemiol, 116(1), 123-140.

Huber, D., Veinante, P. \& Stoop, R. (2005). Vasopressin and oxytocin excite distinct neuronal populations in the central amygdala. Science, 308(5719), 245-248.

Inagaki, T.K. \& Eisenberger, N.I. (2012). Neural correlates of giving support to a loved one. Psychosom Med, 74(1), 3-7.
Inoue, H., Yamasue, H., Tochigi, M., Abe, O., Liu, X., Kawamura, Y., Takei, K., Suga, M., Yamada, H., Rogers, M.A., Aoki, S., Sasaki, T. \& Kasai, K. (2010). Association between the oxytocin receptor gene and amygdalar volume in healthy adults. Biol Psychiatry, 68(11), 1066-1072.

Insel, T.R. (2010). The challenge of translation in social neuroscience: A review of oxytocin, vasopressin, and affiliative behavior. Neuron, 65(6), 768-779.

Institute of Medicine Committee on Health and Behavior. (2001). Health and behavior: The interplay of biological, behavioral, and societal influences. Washington, DC: National Academy Press.

Kamarck, T.W., Manuck, S.B. \& Jennings, J.R. (1990). Social support reduces cardiovascular reactivity to psychological challenge: A laboratory model. Psychosom Med, 52(1), 42-58.

Kaplan, G.A., Salonen, J.T., Cohen, R.D., Brand, R.J., Syme, S.L. \& Puska, P. (1988). Social connections and mortality from all causes and from cardiovascular disease: Prospective evidence from eastern Finland. Am J Epidemiol, 128(2), 370-380.

Karb, R.A., Elliott, M.R., Dowd, J.B. \& Morenoff, J.D. (2012). Neighborhood-level stressors, social support, and diurnal patterns of cortisol: The Chicago Community Adult Health Study. Soc Sci Med, 75(6), 1038-1047.

Karelina, K. \& DeVries, A.C. (2011). Modeling social influences on human health. Psychosom Med, 73(1), 67-74.

Karlin, W.A., Brondolo, E. \& Schwartz, J. (2003). Workplace social support and ambulatory cardiovascular activity in New York City traffic agents. Psychosom Med, 65(2), 167-176.

Kiecolt-Glaser, J.K. \& Greenberg, B. (1984). Social support as a moderator of the aftereffects of stress in female psychiatric inpatients. J Abnorm Psychol, 93(2), 192-199.

Kiecolt-Glaser, J.K. \& Newton, T.L. (2001). Marriage and health: His and hers. Psychol Bull, 127(4), 472-503.

Kim, H.S., Sherman, D.K., Sasaki, J.Y., Xu, J., Chu, T.Q., Ryu, C., Suh, E.M., Graham, K. \& Taylor, S.E. (2010). Culture, distress, and oxytocin receptor polymorphism (OXTR) interact to influence emotional support seeking. Proc Natl Acad Sci U S A, 107(36), 15717-15721.

Kirsch, P., Esslinger, C., Chen, Q., Mier, D., Lis, S., Siddhanti, S., Gruppe, H., Mattay, V.S., Gallhofer, B. \& Meyer-Lindenberg, A. (2005). Oxytocin modulates neural circuitry for social cognition and fear in humans. J Neurosci, 25(49), 11489-11493.

Kirschbaum, C., Klauer, T., Filipp, S.H. \& Hellhammer, D.H. (1995). Sex-specific effects of social support on cortisol and subjective responses to acute psychological stress. Psychosom Med, 57(1), 23-31.

Kirschbaum, C., Pirke, K.M. \& Hellhammer, D.H. (1993). The 'Trier Social Stress Test'-a tool for investigating psychobiological stress responses in a laboratory setting. Neuropsychobiology, 28(1-2), 76-81.

Kissel, S. (1965). Stress-reducing properties of social stimuli. J Pers Soc Psychol, 12, 378-384.

Knox, S.S., Adelman, A., Ellison, R.C., Arnett, D.K., Siegmund, K., Weidner, G. \& Province, M.A. (2000). Hostility, social support, and carotid artery atherosclerosis in the national heart, lung, 
and blood institute family heart study. Am J Cardiol, 86(10), 1086-1089.

Knox, S.S., Theorell, T., Svensson, J.C. \& Waller, D. (1985). The relation of social support and working environment to medical variables associated with elevated blood pressure in young males: A structural model. Soc Sci Med, 21(5), 525531.

Kosfeld, M., Heinrichs, M., Zak, P.J., Fischbacher, U. \& Fehr, E. (2005). Oxytocin increases trust in humans. Nature, 435(7042), 673-676.

Kumsta, R. \& Heinrichs, M. (2013). Oxytocin, stress and social behavior: Neurogenetics of the human oxytocin system. Curr Opin Neurobiol, in press.

Lambert, M.J. (2013). Bergin and Garfield's Handbook of Psychotherapy and Behavior Change (6 ed.). Hoboken, NJ: Wiley.

Lepore, S.J. (1995). Cynicism, social support, and cardiovascular reactivity. Health Psychol, 14(3), 210-216.

Lepore, S.J., Allen, K.A. \& Evans, G.W. (1993). Social support lowers cardiovascular reactivity to an acute stressor. Psychosom Med, 55(6), 518-524.

Levy, R.L. (1983). Social support and compliance: A selective review and critique of treatment integrity and outcome measurement. Soc Sci Med, 17(18), 1329-1338.

Linden, W., Chambers, L., Maurice, J. \& Lenz, J.W. (1993). Sex differences in social support, self-deception, hostility, and ambulatory cardiovascular activity. Health Psychol, 12(5), 376380 .

Love, T.M., Enoch, M.A., Hodgkinson, C.A., Pecina, M., Mickey, B., Koeppe, R.A., Stohler, C.S., Goldman, D. \& Zubieta, J.K. (2012). Oxytocin gene polymorphisms influence human dopaminergic function in a sex-dependent manner. Biol Psychiatry, 72(3), 198-206.

Lowenthal, M.F. \& Haven, C. (1968). Interaction and adaptation: Intimacy as a critical variable. Am Sociol Rev, 33, 20-30.

Luecken, L.J., Suarez, E.C., Kuhn, C.M., Barefoot, J.C., Blumenthal, J.A., Siegler, I.C. \& Williams, R.B. (1997). Stress in employed women: Impact of marital status and children at home on neurohormone output and home strain. Psychosom Med, 59(4), 352-359.

McEwen, B.S. (1998). Protective and damaging effects of stress mediators. N Engl J Med, 338(3), 171-179.

Mendoza, S.P. \& Barchas, R.P. (1984). Social cohesion: Essays toward a sociophysiological perspective. Westport, CT: Greenwood Press.

Meyer-Lindenberg, A., Domes, G., Kirsch, P. \& Heinrichs, M. (2011). Oxytocin and vasopressin in the human brain: Social neuropeptides for translational medicine. Nat Rev Neurosci, 12(9), 524-538.

Olsson, A. (2011). The Impact of Social Cognition on Emotional Learning: A Cognitive Neuroscience Perspective. In Schachtman, T.R. \& Reilly, S. (Eds.), Associative Learning and Conditioning Theory: Human and Non-Human Applications. New York: Oxford University Press.

Olsson, A. \& Phelps, E.A. (2007). Social learning of fear. Nat Neurosci, 10(9), 1095-1102.
Orth-Gomer, K. \& Johnson, J.V. (1987). Social network interaction and mortality. A six year follow-up study of a random sample of the Swedish population. J Chronic Dis, 40(10), 949957.

Parkes, C.M., Benjamin, B. \& Fitzgerald, B.G. (1969). A broken heart: A statistical study of increased mortality among widows. Br Med J, 1, 740-743.

Pasch, L.A., Harris, K.W., Sullivan, K.T. \& Bradbury, T.N. (2004). The Social Support Interaction Coding System (SSICS). In Kerig, P.K. \& Baucom, D. (Eds.), Couple observational coding systems. Mahwah, NJ: Lawrence Erlbaum, pp. 319-334.

Phelps, E.A., Delgado, M.R., Nearing, K.I. \& LeDoux, J.E. (2004). Extinction learning in humans: Role of the amygdala and vmPFC. Neuron, 43(6), 897-905.

Piferi, R.L. \& Lawler, K.A. (2006). Social support and ambulatory blood pressure: An examination of both receiving and giving. Int J Psychophysiol, 62(2), 328-336.

Pressman, S.D. \& Cohen, S. (2005). Does positive affect influence health? Psychol Bull, 131(6), 925-971.

Quirk, G.J., Garcia, R. \& Gonzalez-Lima, F. (2006). Prefrontal mechanisms in extinction of conditioned fear. Biol Psychiatry, 60(4), 337-343.

Reis, H.T. (1996). social support. In Manstead, A.S.R. \& Hewstone, M. (Eds.), The Blackwell Encyclopedia of Social Psychology. Blackwell Reference Online. Oxford, UK: Blackwell Publishing.

Rilling, J.K., DeMarco, A.C., Hackett, P.D., Thompson, R., Ditzen, B., Patel, R. \& Pagnoni, G. (2012). Effects of intranasal oxytocin and vasopressin on cooperative behavior and associated brain activity in men. Psychoneuroendocrinology, 37(4), 447461 .

Rodrigues, S.M., Saslow, L.R., Garcia, N., John, O.P. \& Keltner, D. (2009). Oxytocin receptor genetic variation relates to empathy and stress reactivity in humans. Proc Natl Acad Sci U S A, 106(50), 21437-21441.

Rozanski, A., Blumenthal, J.A. \& Kaplan, J. (1999). Impact of psychological factors on the pathogenesis of cardiovascular disease and implications for therapy. Circulation, 99(16), 21922217.

Sarason, B.R., Pierce, G.R. \& Sarason, I.G. (1990). Social support: The sense of acceptance and the role of relationships. In Sarason, B.R., Sarson, I.G. \& Pierce, G.R. (Eds.), Social support: An interactional view. New York: Wiley \& Sons, pp. 97-128.

Sarason, B.R., Sarason, I.G. \& Shearin, E.N. (1986). Social support as an individual difference variable: Its stability, origins, and relational aspects. J Pers Soc Psychol, 50, 845-855.

Schiller, D., Levy, I., Niv, Y., LeDoux, J.E. \& Phelps, E.A. (2008). From fear to safety and back: Reversal of fear in the human brain. J Neurosci, 28(45), 11517-11525.

Schoenbach, V.J., Kaplan, B.H., Fredman, L. \& Kleinbaum, D.G. (1986). Social ties and mortality in Evans County, Georgia. Am J Epidemiol, 123(4), 577-591.

Schwarzer, R. \& Leppin, A. (1991). Social support and health: A theoretical and empirical overview. Journal of Social and Personal Relationships, 8, 99-127. 
Seeman, T.E. (2000). Health promoting effects of friends and family on health outcomes in older adults. Am J Health Promot, 14(6), 362-370.

Seeman, T.E., Berkman, L.F., Blazer, D. \& Rowe, J.W. (1994). Social ties and support and neuroendocrine function: The MacArthur studies of successful aging. Ann Behav Med, 16, 95-106.

Shrout, P.E., Herman, C.M. \& Bolger, N. (2006). The costs and benefits of practical and emotional support on adjustment: A daily diary study of couples experiencing acute stress. Pers Relatsh, 13(1), 115-134

Singer, T., Seymour, B., O’Doherty, J., Kaube, H., Dolan, R.J. \& Frith, C.D. (2004). Empathy for pain involves the affective but not sensory components of pain. Science, 303(5661), 11571162.

Singer, T., Snozzi, R., Bird, G., Petrovic, P., Silani, G., Heinrichs, M. \& Dolan, R.J. (2008). Effects of oxytocin and prosocial behavior on brain responses to direct and vicariously experienced pain. Emotion, 8(6), 781-791.

Smith, A.M., Loving, T.J., Crockett, E.E. \& Campbell, L. (2009). What's closeness got to do with it? Men's and women's cortisol responses when providing and receiving support. Psychosom Med, 71(8), 843-851.

Spiegel, D. \& Sephton, S.E. (2001). Psychoneuroimmune and endocrine pathways in cancer: Effects of stress and support. Semin Clin Neuropsychiatry, 6(4), 252-265.

Spitzer, S.B., Llabre, M.M., Ironson, G.H., Gellman, M.D. \& Schneiderman, N. (1992). The influence of social situations on ambulatory blood pressure. Psychosom Med, 54(1), 79-86.

Steptoe, A. (2000). Stress, social support and cardiovascular activity over the working day. Int J Psychophysiol, 37(3), 299-308.

Taylor, S.E., Seeman, T.E., Eisenberger, N.I., Kozanian, T.A., Moore, A.N. \& Moons, W.G. (2010). Effects of a supportive or an unsupportive audience on biological and psychological responses to stress. J Pers Soc Psychol, 98(1), 47-56.

Thompson, R.J., Parker, K.J., Hallmayer, J.F., Waugh, C.E. \& Gotlib, I.H. (2011). Oxytocin receptor gene polymorphism (rs2254298) interacts with familial risk for psychopathology to predict symptoms of depression and anxiety in adolescent girls. Psychoneuroendocrinology, 36(1), 144-147.

Tost, H., Kolachana, B., Hakimi, S., Lemaitre, H., Verchinski, B.A., Mattay, V.S., Weinberger, D.R. \& Meyer-Lindenberg, A. (2010). A common allele in the oxytocin receptor gene (OXTR) impacts prosocial temperament and human hypothalamic-limbic structure and function. Proc Natl Acad Sci USA.

Uchino, B.N., Cacioppo, J.T. \& Kiecolt-Glaser, J.K. (1996). The relationship between social support and physiological processes: A review with emphasis on underlying mechanisms and implications for health. Psychol Bull, 119(3), 488-531.

Umberson, D. (1987). Family status and health behaviors: Social control as a dimension of social integration. J Health Soc Behav, 28(3), 306-319.

Uno, D., Uchino, B.N. \& Smith, T.W. (2002). Relationship quality moderates the effect of social support given by close friends on cardiovascular reactivity in women. Int J Behav Med, 9(3), 243-262.

Welin, L., Tibblin, G., Svardsudd, K., Tibblin, B., Ander-Peciva, S., Larsson, B. \& Wilhelmsen, L. (1985). Prospective study of social influences on mortality. The study of men born in 1913 and 1923. Lancet, 1(8434), 915-918.

Wheaton, B. (1985). Models for the stress-buffering functions of coping resources. J Health Soc Behav, 26(4), 352-364.

Young, L.J. \& Wang, Z. (2004). The neurobiology of pair bonding. Nat Neurosci, 7(10), 1048-1054. 